\title{
Atividades culturais e esportivas extracurriculares: influência sobre a vida escolar do discente
}

\section{The influence of artistics, sportives and extracurricular activities in the academic success of students}

\author{
Maria Gabriela Queiroz da Silvai \\ Mônica Caldas Ehrenbergii
}

\begin{abstract}
i Universidade de São Paulo (USP), Faculdade de Educação, São Paulo, SP, Brasil.
mariagabriela.queiroz@hotmail.com

ii Universidade de São Paulo (USP), Faculdade de Educação, Departamento de Metodologia de Ensino e Educação Comparada, São Paulo, SP, Brasil. monica.ce@usp.br
\end{abstract}

\begin{abstract}
Resumo
Apresentando a problemática "O exercício de atividades culturais e esportivas extracurriculares pode influir no rendimento acadêmico do aluno? ”, a presente pesquisa incumbiu-se de investigar a relação da prática de atividades culturais e esportivas extracurriculares no desenvolvimento do estudante. Confrontou-se a pesquisa bibliográfica realizada em plataformas nacionais e internacionais com os dados tabulados, obtidos em um questionário aplicado a estudantes do curso de Licenciatura em Pedagogia da Universidade de São Paulo, presumindo que, ao ingressarem em um vestibular de alta concorrência, tiveram acesso a diversas atividades culturais e esportivas extracurriculares, e esse fator poderia relacionar-se com seu desempenho acadêmico. Concluiu-se que, com a realização de tais práticas, o indivíduo é beneficiado pela melhoria dos diferentes domínios do desenvolvimento, sejam no aspecto motor, afetivo, social e cognitivo, sejam na capacidade de correlacionar habilidades e competências.

Palavras-chave: atividades culturais, práticas extracurriculares, sucesso acadêmico
\end{abstract}




\title{
pro.posıções
}

\begin{abstract}
Curetting the problematic "The exercise of extracurricular cultural and sports activities can influence the academic performance of the student?", this research demands to study the relationship between the practice of cultural and sports activities (extracurricular activities) and the student development, considering hypothetically that it is characterized for improvement of different factors of development, on the motor aspect, affective, social and cognitive, furthermore the student's capacity of correlate abilities and competencies, guiding on a value in qualitative way of the scholar experience, opposing of the grades quantitative system traditional. Is considered like extracurricular cultural and sports activities any exercise absences scholar routine enables the student to work the knowledge and development of own body, of personality, of affective, of socialization, of cognitive, in addition the acquisition and increase of knowledge and cultural repertory, may be music classes, drama classes, artistic expressions, lecture practices, sports practices, and other types.
\end{abstract}

Keywords: cultural activities, extracurricular practices, academic success

\section{Introdução}

Muitas dúvidas permeiam a composição e os fatores que influenciam o sucesso acadêmico. Vários estudos vêm sendo realizados visando desmitificar o que leva o estudante ao aproveitamento qualitativo de sua formação. Alguns autores trabalham com a perspectiva de que algumas pessoas possuem capacidades singulares na sua personalidade, como autonomia, espírito de liderança, maior capacidade de organização dos estudos, disciplina, dentre outros fatores. Ainda dentro da temática, porém com outra visão investigativa, outros pesquisadores discorrem que a prática de atividades esportivas e extracurriculares auxilia os alunos a adquirir competências, que serão fatores influentes diretos do rendimento escolar e atuantes em outros âmbitos da vida do aluno, como o social e o cognitivo. 


\section{pro.posıções}

eISSN 1980-6248

\section{Capital cultural e a trajetória escolar discente}

Para entender a possível relação entre capital cultural e sucesso acadêmico, faz-se necessário um entendimento do conceito bourdieniano. O capital cultural pode se dar de três diferentes formas: incorporado, objetivado e institucionalizado. Quando se apresenta no modo incorporado, supõe um processo de interiorização do conteúdo aprendido no processo de ensino e aprendizagem, tratando-se também de um investimento de tempo e relacionando-se diretamente com o trabalho da escola conjuntamente com a família. Ele se constitui como domínio da pessoa, uma espécie de parte integrante, não podendo ser trocado instantaneamente, e está vinculado à singularidade do ser. Nesse sentido, relacionase com uma transmissão hereditária que se reproduz naturalmente.

A acumulação de capital cultural desde a mais tenra infância - pressuposto de uma apropriação rápida e sem esforço de todo tipo de capacidades úteis - só ocorre sem demora ou perda de tempo, naquelas famílias possuidoras de um capital cultural tão sólido que fazem com que todo o período de socialização seja, ao mesmo tempo, acumulação. Por consequência, a transmissão do capital cultural é, sem dúvida, a mais dissimulada forma de transmissão hereditária de capital. (Bourdieu, 1997, p. 86)

O capital cultural objetivado caracteriza-se por ser um conhecimento transferível a partir de um suporte físico, relacionando-se com as capacidades culturais que permitem que o ser desfrute de bens culturais. Ele pode ser apropriado pelo indivíduo por meio de fatores materiais (capital econômico) ou fatores simbólicos (obras de arte, capital cultural).

O capital cultural institucionalizado se alude ao capital cultural incorporado sob forma de títulos que são garantidos e sancionados legalmente. Pela titulação escolar ou acadêmica, reconhecemos de maneira institucional e oficial o capital cultural possuído por determinado indivíduo.

Além da teoria bourdieniana sobre o acúmulo do capital cultural nos seus três diferentes modos, consideramos que alguns tipos de atividades extracurriculares artísticas e esportivas, além de promoverem sinapses cerebrais entre conteúdos já aprendidos e aqueles que o indivíduo está aprendendo durante a prática, incentivam o desenvolvimento maturacional do cérebro e a capacidade de aprender e desenvolvem muitas habilidades. Por exemplo, jogar xadrez auxilia desenvolver o raciocínio lógico-matemático, bem como tocar um instrumento musical. 


\section{pro.posıções}

Cabe ressaltar aqui que o conceito estabelecido por Bourdieu como "capital cultural" é abordado neste trabalho com o intuito de justificar o ganho e o desenvolvimento de competências relativos ao aluno que se atém a diversas atividades promotoras de cultura (sejam elas de cunho esportivo, artístico, dentre outras) atreladas aos conhecimentos escolares, e não como efeito das atividades culturais e esportivas extracurriculares.

Muito foi estudado sobre a influência da família na escolha da participação ou não das crianças em tais práticas paralelamente ao contexto escolar. Para Duncan (2005, citado por Seabra, 2008), o início de muitos comportamentos saudáveis ocorre no contexto familiar, sendo a família (pais e irmãos) um dos principais fatores de âmbito social capaz de influenciar os comportamentos dos adolescentes. Assim, é a família o primeiro provedor de capital cultural de um ser. Cabe também à instituição familiar reconhecer determinada significância e valor inicial de realização de tais práticas e transmiti-los para o indivíduo em formação, ação essa que pode determinar a relação indivíduo-atividades extracurriculares.

Para reforçar esses resultados, parece-nos importante destacar dois estudos internacionalmente referenciados. ... No estudo de Moore, conduzido em 100 crianças dos 4 aos 7 anos de idade e respectivos progenitores, foi evidente que, quando o pai é fisicamente ativo, a propensão para a criança ser ativa é 3,4 vezes superior à de uma criança cujo pai é inativo. Por outro lado, quando a mãe é fisicamente ativa, a sua propensão é 2 vezes superior. Finalmente, quando os dois progenitores são fisicamente ativos, tal propensão é 7,2 vezes superior à de outras crianças cujos progenitores sejam fisicamente inativos. Na pesquisa de Freedson \& Evenson, realizada em 30 crianças dos 5 aos 9 anos de idade e seus progenitores, verificou-se a existência de uma relação de forte magnitude entre o número de progenitores ativos e os níveis de atividade física evidenciados por essas crianças. Quando os pais eram muito ativos, aproximadamente 93\%-97\% das crianças também eram muito ativas. (Seabra, 2008, p. 729)

A influência familiar na decisão da criança é tão relevante que o próprio autor afirma que, na adolescência, o índice de participação nessas atividades tende a cair, o que pode ser resultado da autonomia que o adolescente desfruta (o que não ocorre na infância) e do fato de o aluno passar mais horas nas instituições de ensino regular, no caso dos estudantes europeus. Na realidade brasileira, a preparação para a demanda do vestibular ou da vida profissional, - muitos estudantes do Ensino Médio brasileiro frequentam cursinhos ou ensino técnico profissionalizante em paralelo à sua formação escolar-, pode explicar esse declínio. 


\section{pro.posıções}

eISSN 1980-6248

Além da influência exercida pelos pais na decisão de praticar atividades extracurriculares, os autores destacam que existe uma relação positiva entre situação socioeconômica e atividades físicas. Adolescentes com uma elevada renda financeira tendem a participar mais de atividades físicas do que aqueles com menor posição econômica. A população de baixa renda enfrenta alguns agentes dificultadores, como: falta de verba para subsidiar tais práticas, obrigações para com o sustento da própria família como mão de obra adicional e assunção de paternidade ou maternidade na adolescência.

Monteiro, Castro, Almeida e Cruz (2009) estudaram o percurso acadêmico de alunos que apresentavam um elevado rendimento (qualitativo e quantitativo) nas áreas de engenharia e de ciências da computação, indagando sobre a possibilidade de qualquer indivíduo que treina e se esforça diante uma determinada tarefa obter níveis de excelência na sua realização, ou se a base do seu trabalho consiste em outros fatores associados que permitam ao indivíduo persistir até atingir o seu rendimento máximo ou dirigir-se sempre para um nível de rendimento superior. Os autores identificaram, em sua pesquisa, que existe a presença de um conjunto de variáveis comuns no percurso acadêmico dos sujeitos. As falas dos entrevistados enfatizaram a capacidade de trabalho, o esforço e a persistência. Foi perceptível também o envolvimento em atividades de planejamento, monitorização e avaliação, definindo objetivos e metas voltados à aprendizagem e à motivação.

Lipscomb (2007) se interessou em saber se a participação em tais atividades tem relação com um aproveitamento qualitativo ligado ao efeito na aprendizagem. Para chegar aos resultados de seus estudos, consultou dados de entrevistados que se juntam ao sair de clubes ou práticas esportivas em um determinado ano, o que permite analisar a chance da performance acadêmica estar relacionada com mais um ano adicional de participações em tais práticas. A análise empírica partiu de dados do segundo acompanhamento do documento americano Estudo Longitudinal de Educação Nacional de 1988. A amostra entrevistada consistiu em alunos da oitava série de tal ano que, posteriormente, foram reentrevistados em 1990 e 1992. Em cada ano, os estudantes responderam detalhadamente sobre seu envolvimento em clubes organizados na escola e seus congruentes durante os 12 meses anteriores, o que permitiu mapear o envolvimento dos alunos em tais atividades. A pesquisadora se preocupou também em levantar o número de faltas dos alunos por semestre para possibilitar uma análise das razões de uma possível mudança de motivação para ir às aulas. Considerando como estavam suas vidas escolares naquele momento, os 


\section{pro.posıções}

eISSN 1980-6248

alunos eram indagados, anualmente, o quão longe eles chegariam na vida acadêmica. Para responder a esse questionamento, eles puderam escolher entre seis opções, que iam desde não terminar o Ensino Médio até cursar a pós-graduação.

Em detrimento possivelmente de uma demanda cultural social, notou-se que os homens se voltam mais para atividades esportivas (resultado também evidenciado por Seabra, 2008) e as mulheres para os clubes derivados, que, no ensino regular americano, constituem-se em clubes de dança, teatro, representação estudantil, jornal da escola, coral, entre outros. Os resultados também indicaram que o envolvimento nas práticas extracurriculares beneficiou o aprendizado do aluno no ensino secundário (secundar school). Atividades atléticas estão associadas com dois por cento de aumento nas pontuações de ciências e matemática, e as participações em atividades de clube estão vinculadas a um por cento de aumento nas pontuações da mesma disciplina. Em paralelo, os dois tipos de atividades estão associados a cinco por cento de aumento no desejo de realização do grau de bacharel. Complementando seus resultados, a autora acredita que o envolvimento em atividades extracurriculares proporciona investimentos de curto prazo e retornos vinculados de maneira positiva com o sucesso posterior no mercado de trabalho.

No confronto de diferentes pesquisas sobre os efeitos da participação em atividades extracurriculares no ensino secundário, Holland e Andre (1987) defendem que a participação em atividades foi relacionada com os indicadores positivos de desenvolvimento dos adolescentes. Entendemos aqui como desenvolvimento, o processo progressivo de aprendizagem e de aquisição de conhecimento e habilidades típicas da espécie humana. Desse modo, existe uma correlação entre a participação em tais práticas de atividades esportivas e extracurriculares e as variáveis como boas notas, autoconhecimento, otimismo e melhoria das relações entre os alunos.

Spady (1982, citado por Holland \& Andre,1987) argumenta que os alunos atletas do sexo masculino têm objetivos educacionais mais elevados em relação às suas notas acadêmicas do que aqueles que não são atletas. Sugere também que a participação em atividades culturais (os clubs existentes em escolas americanas) não esportivas relaciona-se a resultados benéficos no âmbito do aproveitamento da formação para os atletas do time do colégio masculino e feminino, o que evidencia que, no caso desses alunos que já participam de atividades esportivas e também se dedicam a essas atividades culturais, existe uma 


\section{pro.posıções}

e-ISSN 1980-6248

correlação entre as experiências vividas e as habilidades adquiridas que servem como fator positivo no aproveitamento dos estudos acadêmicos.

Darling, Caldwell e Smith (2005, citados por Fujita, 2006) afirmam que os adolescentes que participam de atividades extracurriculares apresentam, em sua trajetória, notas mais elevadas do que o restante dos alunos, acompanhadas não só de atitudes mais positivas em relação à escola, como também aspirações superiores na carreira acadêmica.

Seguindo os preceitos de Marsh (1999, citado por Broh, 2002) e Fejgi (1999, citado por Broh, 2002), foi pesquisado o grau que três fatores apresentam na vida dos alunos: autoestima, disciplina e tempo dedicado à lição de casa. Acreditam eles que as práticas esportivas agem sob a autoestima e a disciplina, e elas nos resultados acadêmicos. Foi também analisado o tempo que o aluno usou para realizar as lições de casa semanalmente nos anos que cursou o Ensino Médio e, ao confrontar esse dado com as suas notas, observaram que há uma relação direta progressiva entre maior tempo de estudo em casa e rendimento escolar.

Broh (2002) verificou a relevância da participação e da frequência de conversa dos alunos com os pais sobre a escola, seus cursos e atividades, e pôde evidenciar uma relação positiva entre os alunos que responderam "sempre" e o seu rendimento escolar, dado que concorda com as demais referências bibliográficas presentes neste artigo.

Acerca da participação direta em atividades esportivas, também concluiu que participar de esportes interescolares durante todo o Ensino Médio está relacionado à melhoria das notas de inglês e ao desempenho nos testes de matemática, mas não nos de leitura.

\footnotetext{
A participação em diferentes tipos de esportes pode afetar diferentemente no desempenho acadêmico. Por exemplo, enquanto esportes de equipe pode levar a fortes laços sociais de pares (capital social), esportes individuais podem construir uma ética de trabalho individual mais forte e capacidade de controle. (Broh, p. 86, 2002)
}

O capital cultural, definido por Bourdieu (citado por Dumais, 2006) como "competência linguística e cultural proveniente da relação familiar com a cultura e que pode ser produzida pela educação familiar quando ela transmite a cultura dominante" (p.122), explica, em parte, a atuação de práticas esportivas na melhoria de matemática e inglês. Ainda na linha de pensamento sobre a relevância do capital cultural, o artigo do autor 


\section{pro.posıções}

10.1590/1980-6248-2015-0055

conclui que a participação em diferentes tipos de esportes e atividades afeta diferentemente o desempenho acadêmico. $\mathrm{O}$ aluno que participa de diversas atividades extracurriculares e esportivas obtém um resultado mais satisfatório em sua vida acadêmica, graças à relação realizada por ele das experiências vivenciadas em tais atividades com as experiências de estudo, ao desenvolver várias competências do ser como as cognitivas, as motoras, as sociais, entre outras. O capital cultural alude-se, nessa instância, ao capital social, tido como a capacidade de acumular benefícios de pensamentos em redes sociais (Bourdieu, citado por Broh, 2002), e construído por qualquer tipo de relação social, como com familiares, pares da mesma idade, professores, dentre outros.

\section{O capital cultural na práxis dos licenciandos em Pedagogia da Universidade de São Paulo}

Para embasar os resultados deste trabalho e contribuir com as análises, foi realizada uma pesquisa bibliográfica em plataformas prioritariamente nacionais e, devido à escassez de referências sobre determinada temática, foram consultadas também algumas fontes bibliográficas internacionais.

Do total de artigos selecionados na pesquisa realizada pelas palavras-chave do projeto em periódicos nacionais e internacionais, foi realizado o fichamento de sete pesquisas, cujos objetivos se assemelhavam em algum aspecto com o presente projeto. Como o número de artigos encontrados relacionados ao tema fosse pequeno, optamos por iniciar a parte de coleta dos dados quantitativos.

Assim, partindo das constatações retiradas das pesquisas dos referidos autores, elaboramos um questionário, composto por nove questões, que buscavam verificar se havia semelhança entre o perfil de formação escolar, participação parental, prática de atividades extracurriculares, dentre outros fatores, do público-alvo desses estudos com o nosso público-alvo. Se as considerações sobre a prática dessas atividades, os benefícios que podem trazer para o aluno e sua relação com o sucesso escolar não seriam fatores limitantes ao ingresso no curso e na faculdade em questão, mas, sim, crença de que tais práticas garantiriam o desenvolvimento dos estudantes dentro de seu contexto individual 


\section{pro.posıções}

e-ISSN 1980-6248

escolar, familiar e social, favorecendo-lhes o ingresso no curso, por meio da integração entre os saberes e habilidades adquiridos pelas práticas, bem como a aquisição de outras conquistas desejáveis no processo educacional, tais como: formação da cidadania, altruísmo, autonomia e capacidade de realização de planos.

O público-alvo foi composto por estudantes da graduação em Pedagogia da Universidade de São Paulo, partindo do pressuposto que, por terem sido aprovados em um dos vestibulares mais concorridos do Brasil, obtiveram êxito em sua vida escolar, o que justifica a escolha, a priori, por alunos apenas de tal instituição para esta pesquisa.

O questionário foi elaborado na plataforma SurveyMonkey, e, após ser disponibilizado na plataforma online, teve divulgado o seu link de acesso para a lista de $e$ mails da graduação da Faculdade de Educação da Universidade de São Paulo.

Após o término da coleta de dados, por meio do questionário, realizamos a tabulação acompanhada de análise dos dados obtidos, confrontando-os com as bibliografias selecionadas.

Foram entrevistados, por meio da plataforma online "SurveyMonkey", 56 graduandos aleatórios. A escolha de tal público-alvo justificou-se pelo ingresso em um vestibular de concorrência elevada no Brasil. Devido à voluntariedade da participação dos respondentes, acreditamos que as características descritas, a seguir, dessa parcela dos estudantes do curso, caracterizam e ilustram a realidade da parte majoritária dos alunos do curso de Pedagogia da Universidade de São Paulo.

No que tange à posição socioeconômica, os 56 alunos que responderam ao questionário apresentaram resultados balanceados. Enquanto 30,36 \% se enquadram na renda de três a quatro salários mínimos por pessoa em seu núcleo familiar, outros 28,57\% ocupam a posição de mais de oito salários mínimos, caracterizando-se como classe "A" da pirâmide econômica brasileira. Mesmo a outra porcentagem que ocupa a categoria de três a quatro salários mínimos por pessoa, possui uma renda per capita familiar considerada diferenciada (e economicamente mais favorável) do que a maioria dos demais universitários brasileiros e jovens da mesma faixa etária.

Tal condição econômica não apenas garante a realização de práticas extracurriculares, mas facilita o acesso à universidade, pois, na concorrência do processo seletivo do vestibular, os jovens com esse perfil socioeconômico privilegiado (que se trata 


\section{pro.posıções}

eISSN 1980-6248

da minoria da população da mesma faixa etária) partem de uma posição diferente dos demais concorrentes que, além de não terem a mesma condição que lhes garantiu acesso ao capital cultural por meio de tais práticas, podem apresentar alguns fatores que permeiam como agentes dificultadores no acesso à universidade. Essa espécie de círculo vicioso da desigualdade social acaba garantindo ao público que se encaixa na classificação socioeconômica como elite o acesso não só ao capital cultural objetivado, mas também ao capital cultural institucionalizado. A hegemonia desse grupo dominante é reforçada pelo sistema capitalista, o que dificulta a mobilidade social da classe proletariada.

Ao verificar a participação dos pais em relação à vida escolar e à realização de práticas extracurriculares, segundo a perspectiva de Duncan (2005, citado por Seabra, 2008), que considera os pais como primeiros provedores de capital cultural para os filhos e potencial influenciador em suas escolhas, 57,14\% dos entrevistados afirmaram que possuíam o hábito de conversar frequentemente com os pais sobre os estudos, os cursos e as atividades extracurriculares realizadas e contavam com a orientação parental nas escolhas de tais atividades.

Os resultados apresentados nos questionários também aludem ao estudo de Fujita (2006), que sugere que a forma como as crianças gastam seu tempo não escolar, combinado com o acompanhamento dos pais em diversos âmbitos da vida dos filhos, apresenta influência direta progressiva em seu desempenho escolar.

No que tange à disciplina pessoal de estudos em casa, 30,36\% do público-alvo declarou que dedica a eles entre três e seis horas por semana. Marsh (1999, citado por Broh, 2002) e Fejgi (1999, citado por Broh, 2002) se indagam se apenas a prática de atividades esportivas e extracurriculares garante benefícios relacionados ao sucesso acadêmico. Os autores confrontaram os dados de suas pesquisas que mostraram uma relação direta progressiva entre horas gastas em casa com estudo e notas mais elevadas, julgando o tempo gasto com estudos fora do ambiente acadêmico um dado importante que pode beneficiar o aluno, aliado com a prática dessas atividades.

Dentre os grupos de atividades esportivas e extracurriculares mais cursados durante a trajetória escolar dos licenciandos em Pedagogia (jogos, idiomas, aulas de música, aulas artísticas, aulas de teatro, aulas de dança, esportes e outros), estão os grupos de esportes e idiomas, sendo que a prática dessa última categoria pode se relacionar com uma exigência 


\section{pro.posıções}

eISSN 1980-6248

do próprio mercado acadêmico e profissional, em que é desejável o conhecimento de outras línguas. Considerando a predominância do gênero feminino no corpo discente da Licenciatura em Pedagogia da Universidade de São Paulo, é perceptível que algumas atividades culturais, como coral, teatro, aulas de dança também apareçam com uma frequência elevada de resposta, em detrimento, possivelmente, dessa predominância de um dos gêneros. Na pesquisa de Lipscomb (2007), também é aparente o maior envolvimento em tais atividades pelos participantes do gênero feminino.

Sobre as razões que os levaram a realizar tais práticas, $71,43 \%$ declararam que a afinidade com a prática os motivou a se dedicar às atividades, enquanto 44,64\% manifestaram o interesse de desenvolvimento e aprimoramento motor e 41,07\% alegaram a vontade de adquirir ou melhorar habilidades relacionadas com a prática de tal atividade no âmbito profissional ou pessoal.

Durante a graduação, 42,86 dos respondentes não continuaram fazendo as mesmas atividades que realizavam durante a vida escolar, mas começaram a se dedicar a outras práticas extracurriculares e esportivas promotoras do capital cultural. Esse fator evidencia a necessidade de atender a algumas demandas acadêmicas, pois, entre as respostas obtidas sobre quais seriam essas práticas, os cursos de línguas (que não se restringem ao inglês), os grupos de estudos, os grupos de liderança estudantil, a participação em núcleos da faculdade, a iniciação científica, ganharam espaço, notando-se claramente que o leque de atividades esportivas, artísticas, de dança e de música declaradas pelos questionados do tempo atual da graduação é menor, se comparado ao da vida escolar. O menor número de atividades práticas refere-se também à peculiaridade da organização do tempo na graduação, sendo que, além das disciplinas mínimas há de se cumprirem, ainda, 450 horas de estágio supervisionado no decorrer do curso.

Quando questionados sobre o tempo que dedicam às atividades declaradas no parágrafo anterior, $50 \%$ dos respondentes declararam gastar de uma a três horas por semana. Esse número indica um valor menor de horas dedicadas a tais práticas, comparando-se à dedicação voltada para elas durante a vida escolar. Podemos justificar essa mudança de hábito com o mesmo motivo encontrado por Seabra (2008), quando ele afirma que, na adolescência e na idade adulta, a assiduidade da participação nessas atividades tende a cair, em função da autonomia que o indivíduo mais velho desfruta e do fato de o discente precisar se dedicar mais tempo aos estudos, seja ainda no Ensino Médio (com cursos 


\section{pro.posıções}

eISSN 1980-6248

profissionalizantes, cursinhos pré-vestibulares) ou na faculdade, cumprindo as exigências mínimas do curso que transpõem as horas gastas na sala de aula, com estágios, estudos independentes, elaboração de trabalhos vinculados às disciplinas, dentre outros. O mesmo pode acontecer com adolescentes e universitários que conciliam a frequência à instituição de ensino regular com o trabalho remunerado.

Ao responderem sobre suas participações em grupos de liderança estudantil, os alunos mencionaram: grêmio, centro acadêmico, União Estadual dos Estudantes, movimento estudantil, representação discente e atlética. As seguintes justificativas foram alegadas com mais frequência pelos $78,57 \%$ dos alunos que não participaram de tais grupos: falta desses movimentos em sua escola (o que indica uma demanda escolar que precisa ser repensada nessas escolas cuja prática é inexistente, pois a presença de um grupo de representação estudantil colabora para a formação de um indivíduo crítico, politizado e para a promoção da democracia), falta de tempo para se dedicar, falta de interesse (o que também pode estar relacionado à não promoção desses movimentos pela escola), dentre outros.

Apesar de 57,14\% dos entrevistados responderem que obtiveram uma participação direta dos pais durante o processo escolar e até mesmo aconselhamento parental sobre a realização de tais práticas, apenas $26,79 \%$ afirmaram ter se dedicado às práticas que escolheram por incentivo de familiares, amigos ou professores. Esse dado pode indicar um possível desenvolvimento de autonomia relacionado à vida adulta para o aluno saber ponderar sobre os incentivos e os estímulos que recebe de outrem e tomar decisões sobre o próprio percurso da vida acadêmica, pessoal e profissional, o que também pode ser considerado como um benefício proveniente de tais práticas.

Ao responderem sobre os benefícios que julgaram obter por causa da prática de tais atividades, 55,36 \% afirmaram que desenvolveram motivação, autonomia e autoconfiança na capacidade de resolver problemas, e a mesma porcentagem de questionados declarou que desenvolveram também o autoconhecimento do corpo e de suas capacidades. Um total de $51,79 \%$ dos questionados declararam que obtiveram o desenvolvimento do espírito de liderança, oratória e capacidade de socialização, bem como o desenvolvimento da capacidade de expressão corporal. 


\section{pro.posıções}

Tais benefícios encontrados pelos entrevistados de Monteiro et al (2009), mencionados anteriormente, assemelham-se aos declarados pelos alunos da Licenciatura em Pedagogia da Universidade de São Paulo, sendo que mais da metade dos discentes universitários também afirmaram que a prática de tais atividades colaborou para o conhecimento das potencialidades corporais, que se trata de um benefício pouco estudado nas demais pesquisas sobre o assunto.

Darling et al (2005, citados por Fujita, 2006) afirmam que os adolescentes envolvidos com as práticas de tais atividades também apresentam notas mais elevadas do que o restante dos alunos, agregadas à atitudes positivas em relação à escola e às aspirações acadêmicas superiores. Características que podem ter estado presentes na vida dos discentes da Licenciatura em Pedagogia na Universidade de São Paulo, auxiliando-os no ingresso por meio do vestibular.

A pesquisa de Broh (2002) constatou que a prática de esportes promoveu o diálogo entre o aluno e os pais sobre os assuntos concernentes à escola. Os entrevistados também declararam que esse diálogo sobre a vida escolar se estendeu aos professores fora do horário letivo, o que pressupõe um aumento na socialização, na expressão e na autonomia discentes, benefícios também mencionados pelo público-alvo desta pesquisa.

\section{Considerações finais}

Apesar de alguns autores acreditarem que existam indivíduos que possuem características que lhes garantem um aproveitamento acadêmico mais aparente, é possível afirmar que, independente das características que o ser já possui, o capital cultural adquirido por meio da realização de práticas extracurriculares e esportivas, bem como a influência e o acompanhamento parental sobre os diversos âmbitos que constituem a vida do aluno, favorece a aquisição e o desenvolvimento de tais características no indivíduo, potencializando, qualitativamente, seu desempenho acadêmico.

Os alunos da Licenciatura em Pedagogia da Universidade de São Paulo, em sua maioria, apresentam uma média condição socioeconômica (principalmente se comparados 


\section{pro.posıções}

eISSN 1980-6248

ao restante do público da USP), o que garantiu o acesso à realização de um vasto leque de atividades esportivas e artísticas extracurriculares durante sua trajetória escolar. Eles contaram com uma participação parental assídua durante sua formação e obtiveram alguns benefícios semelhantes aos concedidos aos públicos-alvo de outras pesquisas com a mesma temática. O fato de que, apesar de não apresentarem uma elevada situação socioeconômica e, mesmo assim, terem tido a oportunidade de praticar atividades extracurriculares, podemos relacionar com a valorização parental dessas práticas ou com o acesso a alguma política que subsidiou a participação nessas atividades para esses discentes.

Ressalvamos que, ao trabalhar com um público-alvo que teve acesso à transmissão de capital cultural via família e escola e conseguiu ingressar em um vestibular de concorrência elevada, o sucesso acadêmico não deve ser entendido de modo restrito ao ingresso no curso e na universidade em questão, mas deve ter em conta o aproveitamento qualitativo dessas vivências extracurriculares e esportivas. Entendemos também que, visto que o capital cultural foi garantido na trajetória educacional dos entrevistados, a possibilidade de os resultados apontarem para uma relação positiva entre a prática de atividades extracurriculares e esportivas e a vida escolar do discente é favorecida.

A similaridade desses fatores ao longo da vida escolar desses indivíduos implica em uma relação positiva dessas características que relacionam o acesso ao capital cultural ao sucesso acadêmico, que aqui pode ser descrito como a consequência do acúmulo do capital cultural adquirido com a correlação dos saberes internalizados pelo indivíduo por meio da aquisição desse capital cultural e que resultam em benefícios nos âmbitos pessoais e profissionais da vida do ser. Isso porque eles se relacionam com a prática acadêmica propriamente dita, formando uma espécie de círculo vicioso e natural, que sugere uma relação de causa-consequência entre a aquisição de capital cultural por meio das práticas extracurricularese o sucesso acadêmico, conforme sugere o esquema da Figura: 


\section{pro.posıções}

eISSN 1980-6248

Relação entre a aquisição de capital cultural por meio das práticas extracurriculares e o sucesso acadêmico

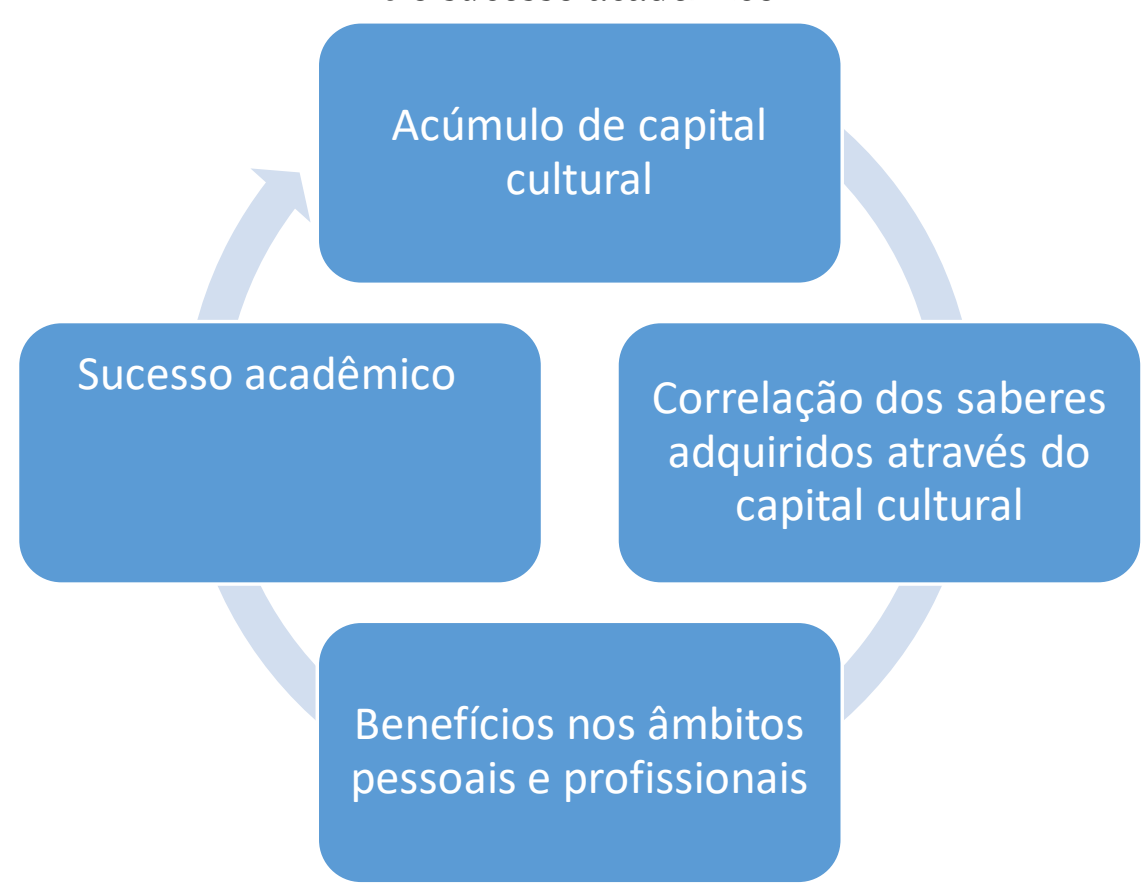

$\mathrm{Na}$ Figura, a aquisição de capital cultural é tida como ponto inicial para as outras etapas que resultarão no sucesso acadêmico. Essa espécie de "bagagem", proveniente primeiramente do núcleo familiar, comporá o repertório que a criança utilizará para fazer correlações entre os seus conteúdos e se desenvolver a partir do confronto dessas informações, adquirindo benefícios que concernem ao campo pessoal e profissional de suas vidas. A partir desses fatores beneficiários, o aluno desenvolverá características e práticas que o poderão conduzir ao sucesso acadêmico, que resulta na confirmação da obtenção do capital cultural, gerando outro acúmulo de capital por meio do capital cultural institucionalizado, recomeçando novamente o ciclo que relaciona o acúmulo de capital cultural com o sucesso acadêmico, presumindo que, de quanto mais desse acúmulo o aluno for provido, maior será a sua capacidade de correlacionar saberes e desenvolver benefícios que se correlacionam com o sucesso acadêmico.

Ao afirmar que existe um impacto diferente na vida acadêmica em relação a cada esporte ou atividade extracurricular exercida, Broh (2002) confirma uma hipótese levantada inicialmente no presente estudo: o discente vinculado a diversas atividades esportivas e culturais atinge um resultado mais positivo no que concerne à vida acadêmica, a partir das 


\section{pro.posıções}

eISSN 1980-6248

relações que pode fazer com a vivência das práticas e com o conteúdo acadêmico, desenvolvendo várias habilidades que pertencem à vida do indivíduo, dentre elas as cognitivas, as motoras e as sociais.

Como resultado da pesquisa realizada, afirmamos que a prática das atividades esportivas e artísticas exercidas extracurricularmente transcende o benefício de composição e enriquecimento do capital cultural do aluno, uma vez que, além de desenvolver competências já mencionadas, induz o discente a uma melhoria atitudinal embasada em práticas assertivas que variam desde a sua disciplina e organização para o tempo do estudo, até o desenvolvimento de práticas sociais mais bem-sucedidas.

Em diversos artigos da bibliografia selecionada, o papel da família foi evidenciado como relevante não só como pioneiro de aquisição de capital cultural de um ser, mas como forte influência na realização de práticas esportivas e extracurriculares e no acompanhamento da vida escolar. Esse fato nos encaminha para a questão do trabalho conjunto entre escola e família que, aparentemente, se faz muito presente na vida escolar e acadêmica dos participantes das pesquisas que compõem a referência bibliográfica, mas que foge um pouco da realidade da parte majoritária da população brasileira. Serve como indicador da relevância da participação dos pais na educação dos filhos e denuncia uma tendência nacional em que o papel educacional é transferido integralmente da família para a escola, prejudicando a potencialização da influência participativa parental na vida escolar do discente desde o Ensino Básico até o universitário.

A aparente relação entre capital cultural e sucesso acadêmico presente nos resultados desta pesquisa sugere que um agravante direto do não acesso à universidade, logo ao sucesso acadêmico, pelas camadas menos abastadas da população está não só relacionado à condição socioeconômica e à desigualdade social, mas, também, a um não acesso mínimo a instituições, políticas e ações que garantam a aquisição do capital cultural que embasa o processo do desenvolvimento social, afetivo, cognitivo e motor. Trata-se de uma questão de justiça escolar. A escola deve efetivar o seu papel como promovedora do saber e da aquisição do capital cultural, continuando a aquisição do capital cultural já iniciada em casa. Como esse direito da criança muitas vezes não é garantido em todos os núcleos familiares, o trabalho na escola acaba se iniciando em patamares diferentes dentro da própria sala de aula, o que pode acarretar desigualdade no âmbito escolar propriamente dito. 


\section{pro.posıções}

e-ISSN 1980-6248

Isso sugere que alguns estudos far-se-ão necessários sobre a prática docente e a organização pedagógica necessárias para suprir essa demanda e promover a maior aquisição de capital cultural possível, garantindo uma aproximação eficiente e linear do desenvolvimento dos alunos, que dependerá da aquisição dessa bagagem cultural -capital incorporado. É importante considerarmos que, apesar da importância da capacidade do professor em promover a máxima igualdade possível na aquisição do capital cultural pelos seus alunos, a sua totalidade é impossível, visto que a cultura é um patrimônio humano transmitido pelos primeiros seres humanos com quem as crianças têm contato.

É relevante afirmar também que algumas condições mínimas e subsidiais que garantem e promovem a aquisição do capital cultural, especialmente para as famílias mais pobres (capital objetivado), precisam ser encaradas como políticas públicas que invistam na educação e na cultura como base para a redução e o combate da desigualdade social e o desenvolvimento do País, tratando-se também de um direito da criança se relacionar diretamente com a eficiência da sua vida escolar. 


\section{pro.posıções}

\section{Referências Bibliográficas}

Bourdieu, P. (1997). Capital cultural, escuela y espacio social (pp. 75-96). México: SigloVeinteuno.

Broh, B. A. (2002, janeiro). Linking extracurricular programming to academic achievement: Whobenefits and why. Sociology of Education, 75(1), 69-91.

Dumais, S. A. (2006, March). Elementary School students' extracurricular activities: the effects of participation on achievement and teacher's evaluations. Sociological Spectrum, 26(2), 117-147.

Fujita, K. (2006). The effects of extracurricular activities on the academic performance of junior high students. Undergraduate. Research Journal for the Human Sciences (vol. 5).

Holland, A., \& Andre, T. (1987, winter). The effects of participation in extracurricular activities in secondary school: What is known, what need to be know? Review of Educational Research Winter, 57(4) 437-466.

Lipscomb, S. (2007, August). Secondary school extracurricular involvement and academic achievement: a fixed effect approach. Economics of Education Review, 26(6), 463-472.

Monteiro, S., Castro, M., Almeida, L., \& Cruz, J. F. A. (2009). Alunos de excelência no ensino superior: comunalidades e singularidades na trajectória académica. Aná. Psicológica [online], 27(1), 79-87.ISSN 0870-8231.

Seabra, A. (2008). Determinantes biológicos e sócio-culturais associados à prática de atividade física de adolescentes. Cad. Saúde Pública, 24(4), 721-736.

Submetido à avaliação em 24 de maio de 2015 ; aprovado para publicação em 5 de novembro de 2015. 